\title{
A NOVEL APPROACH OF VERTICAL CITY IN SOUTHERN CHINA UTILIZING CONSTRUCTION ROBOTICS, OPEN BUILDING PRINCIPLES, MODULAR CONSTRUCTION AND PREFABRICATION
}

\author{
Rongbo Hu*, Wen Pan* and Thomas Bock* \\ * Technical University of Munich, Chair of Building Realization and Robotics, Germany \\ e-mails: rongbo.hu@br2.ar.tum.de,wen.pan@br2.ar.tum.de, thomas.bock@br2.ar.tum.de
}

\begin{abstract}
A number of new developments are claimed in the name of "vertical city", yet few represents an important characteristic of a city, which is the ability to constantly transform. Based on the analysis of several successful and unsuccessful precedents of building complexes, this paper aims to propose a novel approach of vertical city featuring constant vertical urban transformation by applying the state-of-the-art construction technologies. Meanwhile, this vertical city approach has the ability to integrate five basic elements of a city: vertical and horizontal circulation systems as its paths, a flexible building envelope as its edges, variable mix-used functional blocks as its districts, sky bridges and roof gardens as its nodes, and the complex itself as a landmark. More importantly, it can change its size, form and function with the help of construction automation technologies and open building principles, and responsively evolve in accordance with social, economic, and environmental shifts in a self-sufficient manner, meanwhile avoiding the risk of being homogeneous with surrounding buildings. Eventually, the complex will perform as a series of interconnected components which act together to form a living organism that performs various functions and purposes such as office, residential, commercial, school, hospital, police station, and infrastructure.
\end{abstract}

Keywords: On-site construction factory, Open building, Modular construction, Vertical city.

\section{INTRODUCTION}

A city is a sophisticated organism which is constantly changing throughout its lifecycle, as a result of economy shifts, demographic change, and environmental pressures. Nowadays, megacities are facing unprecedented issues such as overpopulation, population aging, land shortage, lack of infrastructure, and environmental pressures during the process of uncontrollable urban sprawl. Meanwhile, a considerable number of new developments claim themselves in the title of "Vertical City", yet very few represent the essence of a city. The definition of vertical city cannot be solely judged by its height, usage or investment return, but has to demonstrate the capability of adaption in response to urban transformation. This paper aims to propose a novel approach of vertical city, or in other words Vertical Dynamic Urbanism, featuring constant vertical urban transformation through applying the state-of-the-art construction technologies. Meanwhile, this vertical city approach has the ability to integrate basic elements of a city: vertical and horizontal circulation systems as its paths, a flexible building envelope as its edges, variable mix-used functional blocks as its districts, sky bridges and roof gardens as its nodes, and the complex itself as a landmark. More importantly, it can change its size, form and function with the help of construction automation technologies and open building principles, and responsively evolve in accordance with social, economic, and environmental shifts in a self-sufficient manner, meanwhile avoiding being homogenized with surrounding buildings. Eventually, the complex will perform as a series of interconnected components which act together to form a living organism that performs a variety of functions and purposes. 


\section{METHODS}

\subsection{Lessons learned from two American building projects}

\subsubsection{Pruitt-Igoe, St. Louis, Missouri}

Commonly a building will face an unpleasant destiny when it reaches the end of its lifecycle: to be demolished. Designed by renowned architect Minoru Yamasaki, Pruitt-Igoe, St. Louis is arguably the most infamous failure of American social housing program. Due to poverty, crime, and racial segregation, the overscale complex of 33 buildings were demolished with explosives in 1972, which later became a symbolic event of unreasonable planning and waste of construction resources [1]. This is largely because the traditional building lacks flexibility and variability in its volume, height, and usage (see Figure 1).

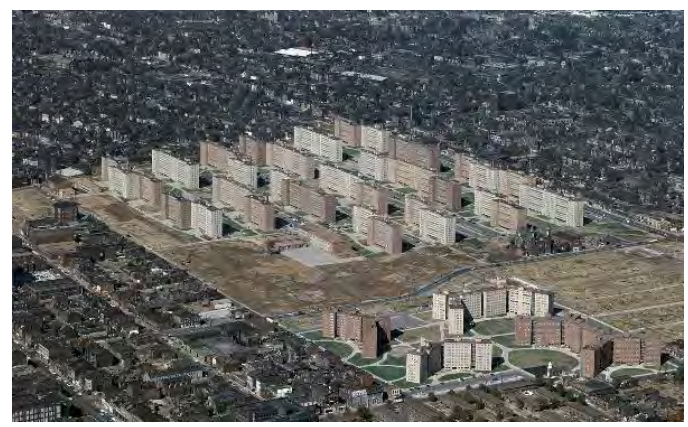

Figure 1. Aerial view of the Pruitt-Igoe complex. Image courtesy of United States Geological Survey (Public Domain).

\subsubsection{Blue Cross Blue Shield Tower, Chicago, Illinois}

Contrary to Pruitt-Igoe, a silver lining can be observed in the design and construction process of Blue Cross Blue Shield Tower in Chicago which is a 57-story two-phased, vertically expanded office tower. The building's 33-story first phase was completed in 1997, and more than 10 years later in 2010, phase two was completed, adding 24 stories on top of the original, fully occupied building. During the expansion process, occupation in the lower original building remains normal and uninterrupted [2]. This example shows that through the innovative concept of vertical expansion, a building can successfully plan for a long-term growth without relocation, thus providing an excellent reference for the future expansion of vertical city (see Figure 2).

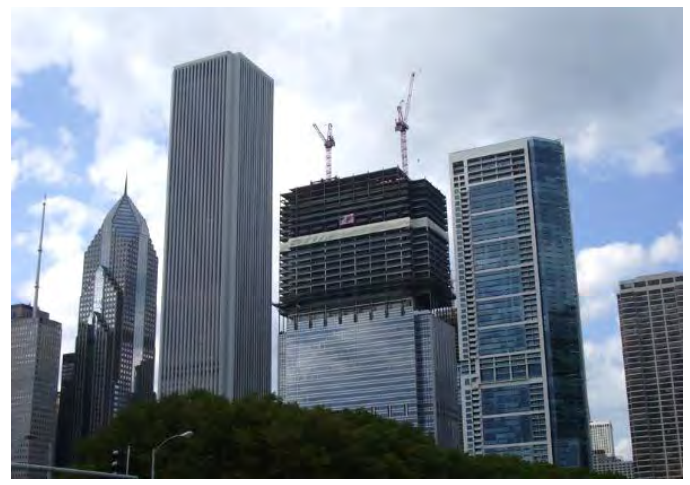

Figure 2: Blue Cross Blue Shield Tower in Chicago under expansion. Image courtesy of Wikimedia user Photogal (Own work, https://commons.wikimedia.org/wiki/File\%3ABlue_Cross_Blue_Shield_Tower.jpg). 


\subsection{State-of-the-art technologies to be applied in the new vertical city approach}

In order to achieve perpetual vertical urban transformation, there are five interconnected concepts and technologies which will serve as the core pillars of Vertical Dynamic Urbanism (see Figure 3). These concepts and technologies will be analyzed in the following sections.

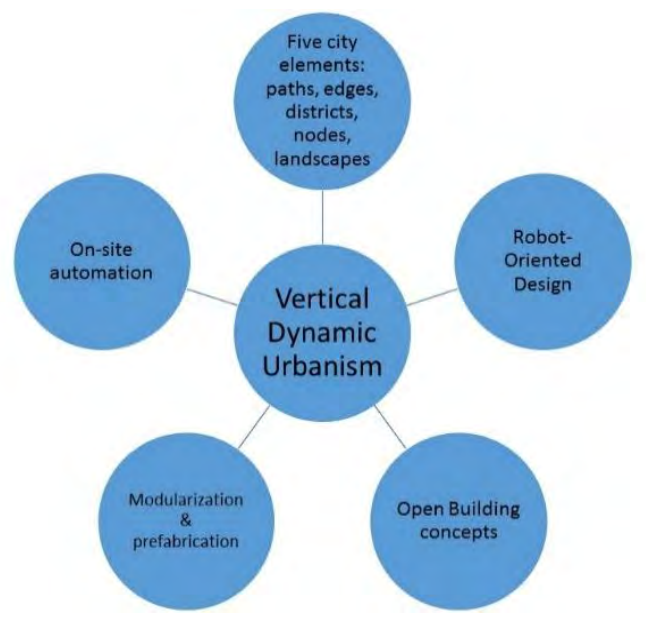

Figure 3: Five pillars in the new vertical city approach.

\subsubsection{Five city elements}

In the book the Image of the City (1960), Kevin Lynch concluded that people formed mental maps of the surrounding urban area through five tangible elements: paths, edges, districts, nodes, and landmarks [3]. Accordingly, in order to achieve the authenticity of a vertical city, these five elements must be interpreted and reflected in the design process. Specifically, the new vertical city has vertical and horizontal circulation systems as its paths, a flexible building envelope as its edges, variable mix-used functional blocks as its districts, sky bridges and roof gardens as its nodes, and the complex itself as a landmark.

\subsubsection{Robot-Oriented Design}

First conceptualized by Thomas Bock in 1988, Robot-Oriented Design (ROD) emphasizes the idea that before the final on-site construction process, all parameters shall have been already considered at the earlier design and production stages. In order to establish determined conditions for robotic on-site operations, the elements of building subsystems (e.g. building structure, component, assembly method, and equipment selection, etc.) need to be geometrically and physically well defined in accordance with robots and automation [4].

\subsubsection{Open Building concepts}

Open Building is a cross-disciplinary approach to the design of buildings that takes account of the possible need to change or adapt the building during its lifecycle, in accordance with social, economic, and technological changes. Open Building concepts gradually emerged in response to evolving social, political and market forces, to prevailing conditions and trends in residential construction, manufacturing and many other factors that demand more efficient and susceptive practices. The building is designed in different levels: support structure, infill system, fit-out and appliances [5]. All these levels have been updated and reinterpreted to utilize the benefits of state-of-the-art industrial production, emerging information technologies, improved logistics and changing social values and market structures. 
Apparently, buildings following Open Building principles will by no means become obsolete, but will perpetually evolve in accordance with occupants' demands.

\subsubsection{Modularization and prefabrication}

Modularization and prefabrication play a significant role during the lifecycle of the new vertical city approach. Usually several levels are defined in building prefabrication: lower-level components made of raw materials and parts (e.g. ceramic, brickwork, concrete, wood, steel, glass, polymers, etc.), mid-level building components (i.e. building subsystem manufacturing, such as kitchen modules, bathroom units, assistance modules, etc.), and high-level prefabricated complete buildings [6]. In the new vertical city approach, all main parts and components of the building will be prefabricated in coordination with Open Building concepts, in order to achieve flexibility and sustainability throughout the lifecycle of the vertical city.

\subsubsection{On-site automation}

Since the late 1980s, Japanese contractors began to realize that payoffs of single-task robots were limited unless more of the construction process could be automated and integrated. Therefore, they began to explore the application of manufacturing principles to construction. There are four fundamental elements in an on-site automation system: (1) an on-site factory protected by an all-weather enclosure, (2) an automated jacking system, (3) an automated material conveying system, and (4) a centralized information control system. Most of the on-site construction factories use just-in-time material delivery system, bar-coded parts or components, and computerized information management system to improve the efficiency and quality of the construction process. Other tasks such as welding, painting, and concrete finishing can be further carried out by single-task construction robots. In addition, the on-site construction factory system can also be applied to the deconstruction process.

For example, Big Canopy, designed by Obayashi Corporation in 1995, was the first automated construction system applied in the construction of precast concrete structures. The Big Canopy itself is supported by four mass independent columns around the building which allow more flexibility than other previous systems. The system has a self-climbing temporary roof. Once the floor was erected, the canopy is jacked up one story at a time and always left a two-story space in between the canopy and the on-site factory floor. Furthermore, the system has a parallel material delivery system which consists of overhead cranes and material delivery lifts (see Figure 4a).

HAT Down method, developed by Takenaka Corporation, is a closed sky factory supported by building itself (moving downwards). The HAT Down system, which can be seen as a reversed on-site construction factory, consists of a series of integrated subsystems: sky factory roof structure, climbing system, horizontal delivery system, lowering shafts, material handling, sorting, and processing yard, realtime monitoring and management system, templates for cutting. In addition, deconstruction site requires some new types of end-effectors, such as material sorting for recycling, water-cutting, and laser-cutting (see Figure 4b) [7]. 

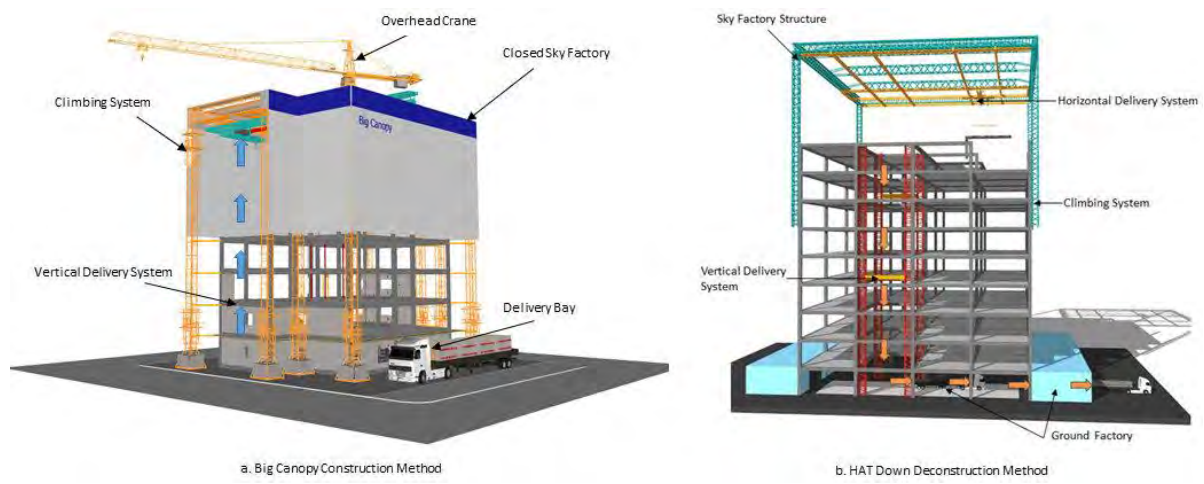

Figure 4: Comparison of Big Canopy Method and HAT Down Deconstruction Method.

\section{RESULTS}

\subsection{Design overview}

The proposed design demonstrates a type of floor plan that is commonly seen in China's construction industry. There are four wings allocated around the central core structure. Each wing consists of ten units, which can be flexibly used as residential, commercial, office, and public use (e.g. school, hospital, police station, infrastructure, etc.) that depends on the requirements of the stakeholders. There are dedicated void spaces located on either side of the wing where the on-site factory self-climbing structures are located (see Figure 5 \& 6).
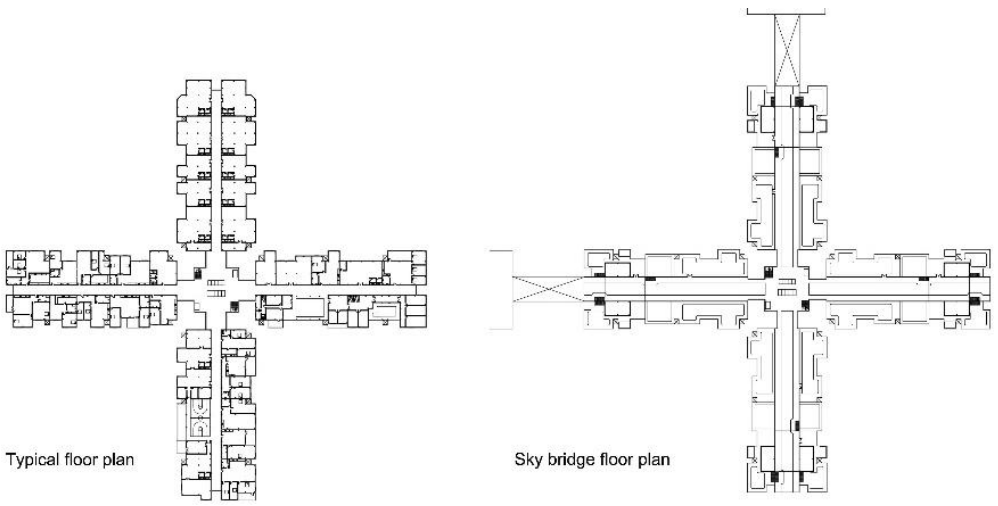

Figure 5: Typical floor plans in the Vertical Dynamic Urbanism complex. 


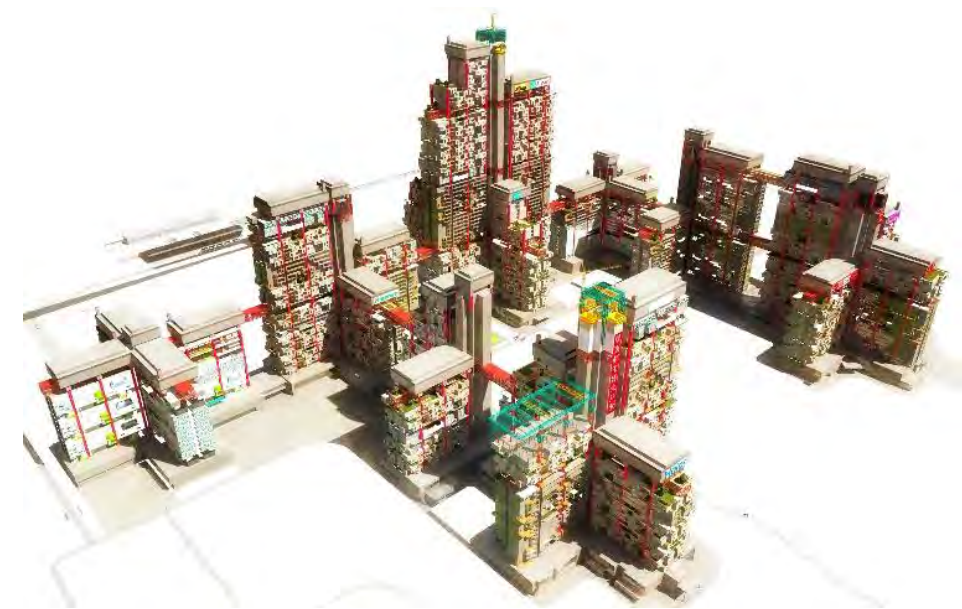

Figure 6: Aerial view of the proposed complex following Vertical Dynamic Urbanism principles.

\subsection{On-site construction factory}

On-site construction factories play a crucial role in the development of Vertical Dynamic Urbanism. With the help of the industrialized building design and the utilization of automation technology, the proposed concept attempts to transform conventional construction sites into on-site assembly environments. Inspired by self-climbing crane and special crane application in the ship building industry, the on-site construction factory (OCF) is designed to assemble the building with minimal human intervention. There is an OCF responsible for the erection process on top of each tower. Each one of them can independently function, extend and retract, and they operate under a specific protocol that improves construction efficiency and safety (see Figure 7).

When the section of the wing is completed, the OCF will be retracted, hoisting equipment will be dissembled, and the vacant frame structure will be lowered in to position and functions as the roof of the building. Apart from the central OCF, each wing OCF equips two automated gantry cranes. The gantry crane will cover the entire construction shop floor of the building. The central OCF benefits from an automated gantry crane and a jib crane. The jib crane is responsible for vertical material transportation for the central OCF and carrying out the initial construction of the other four OCFs.

The hoist module functions as the end effector of the automated gantry crane, which is equipped with the smart crane hoist system to keep delivery balanced as well as to provide vertical and horizontal transportation of the building components. The hoist module also equipped with a sensor-controlled configuration system to help identifying the location of the panel and following pre-programmed assembly sequences [8]. The motion displacement of the robot can be manually operated, and in case of emergency, it will switch into an autopilot control system. The robot control system is connected with the main site control facilities and the project management information system [9]. Once the building components with auto alignment feature reach the correct assembly location, the connections will be fastened by means of dry connection method. Welding and on-site casting will be implemented by singletask construction robots to increase assembly speed.

The vertical material transportation platform is controlled by a lifting planning system that generates a lifting plan based on data such as floor heights, acceleration distance, reduction time, number of stops, construction material input speed, lifting cycle, material transfer speed and waiting time. The data required can be collected from the RFID and ZigBee sensors which are located on the building structure or embedded in the building materials [10]. The base of each tower will function as material loading, sorting and pick-up station during the construction, expansion and maintenance process. A programmable logic controller (PLC) is used for controlling the picking system. At the off-site factory, each building 
component is allocated a RFID tag. When they arrive on site, the tag will be scanned and the information will show the exact assembly sequence and assembly position of each component. Then the components will be placed onto the picking station in the correct order, being ready for lifting and assembly [11].
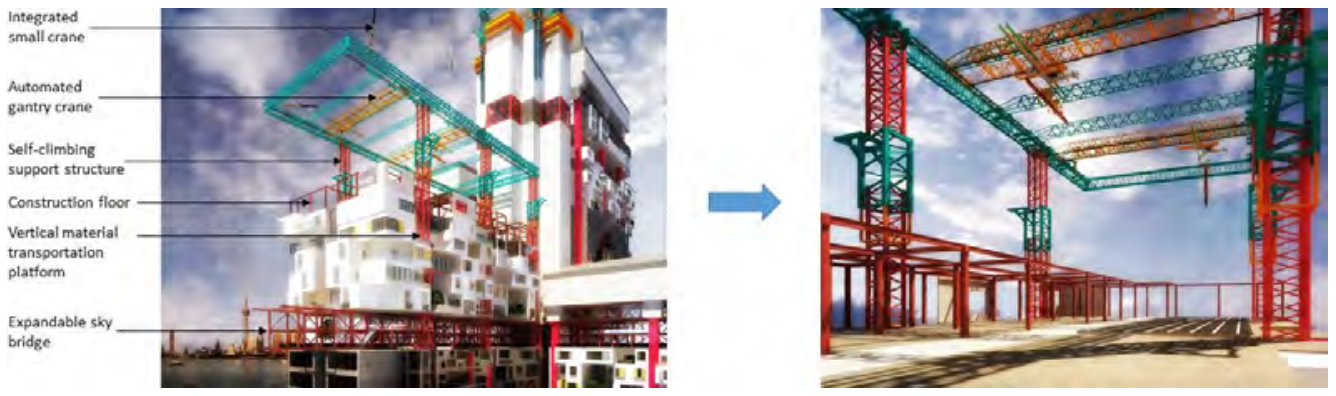

Figure 7: Exterior and interior views of the on-site construction factory.

\subsection{Sky bridge}

The sky bridge, which serves as the main horizontal paths connecting different towers, as well as a community gathering space for multiple activities, will be assembled by the correspondence OCF that depends on the direction where the sky bridge will reach out. The OCF will be extended out by using a smaller integrated crane on the upper deck of the mainframe structure. Then the sky bridge will be constructed by the automated gantry crane. Eventually, the sky bridge shall be interconnected from either side by using integrated retractable assembly systems (see Figure 8 ).
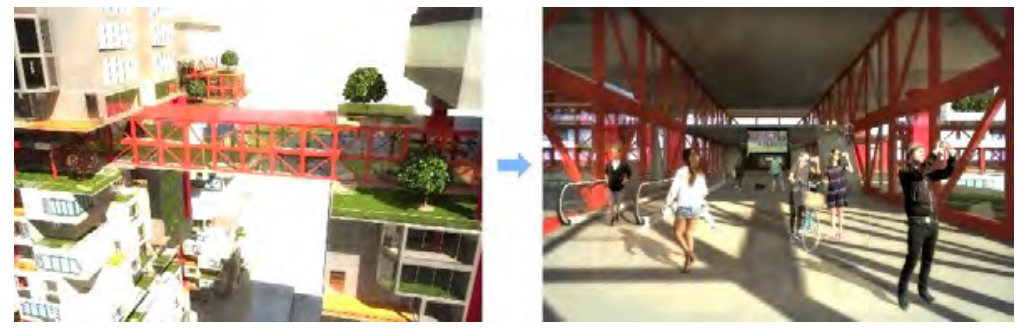

Figure 8: Exterior and interior views of the sky bridge.

\subsection{Open building approach}

Following Open Building concepts, building system of Vertical Dynamic Urbanism can be divided into 4 subsystems: structures, non-load bearing components, services and construction. In general, structural systems include a series of steel beams and columns that are interconnected and provide a flexible box-shaped support system. The prefabricated concrete double ribbed floor panel also classify as part of the structural system. Non-load bearing component systems include precast concrete floor panels and sandwich wall panels. Services system consists of interior fixtures, electrical, plumbing fixtures, and heating, ventilation and air conditioning (HVAC) of the building. Each part can be easily assembled or disassembles so that the building system is able to be upgraded or modified according to the specific demand of each end-user (see Figure 9). 


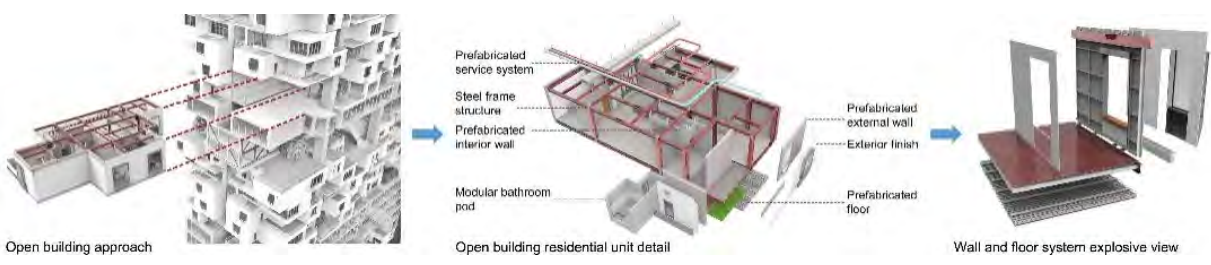

Figure 9: Open building analysis in Vertical Dynamic Urbanism.

\subsection{Development scenario}

In general, the construction of the building follows a bottom-up approach, working from the ground section up. The construction sequence consists of six main procedures. First, the assembly of the initial on-site construction factories. Second, structural assembly, in which the steel beams, columns and the floor components are assembled. Third, external façade finishing. Fourth, service installation, and interior decoration. Fifth, preparation or removal of the temporary installation fixtures, anchor systems. Finally, the entire OCF will be jacked up by the self-climbing structure. The building component will be installed following a programed pattern, a specific sequence of crane and robot manipulations will occur which synchronized by the project control program. When reconfiguration of the building is required, the interior can be easily modified; when relocation and deconstruction are required, deconstruction can be conducted in a reversed order to the construction process. One possible scenario for the future development over the lifecycle of a complex following Vertical Dynamic Urbanism principles is visualized in Figure 10.

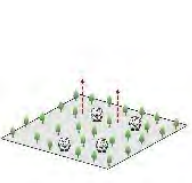

Start (Yaar 0)

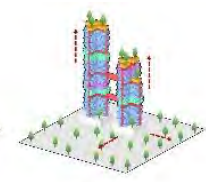

(amne ; Year 5 )

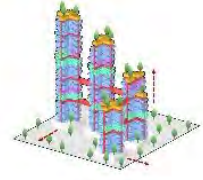

Expanc (rear 20;

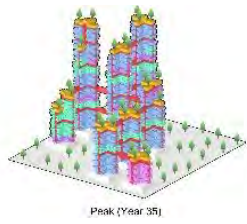

Peak \{Year 35$\}$

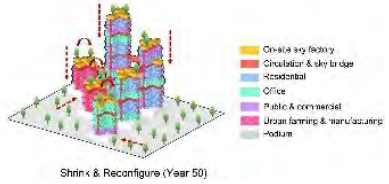

Shrin \& \& Recantigure (Y Yar 50

Figure 10: A typical scenario of 50-years development of a Vertical Dynamic Urbanism complex.

\section{CONCLUSION}

This paper provides a rethink of vertical city in the name of Vertical Dynamic Urbanism, enabling constant vertical urban transformation by applying the state-of-the-art building concepts and technologies. Five interconnected concepts and technologies constitute Vertical Dynamic Urbanism, including five city elements, Robot-Oriented Design, Open Building concepts, modularization and prefabrication, and onsite automation. In addition, this paper will raise public awareness and promote involvement for the research and development of construction automation and robotics. Furthermore, this paper can assist architects and urban planners to formulate a future framework for building design, urban planning, and policy-making process which will benefit all potential stakeholders, and provide an inspiring way of thinking to tackle the aforementioned serious issues such as overpopulation, population aging, land shortage, lack of infrastructure, and environmental pressures.

Nowadays, due to the improvement of medical care standard, the enhanced social security level, and the implementation of the three-decade long one-child policy (recently replaced by two-child policy since 2015), China is about to accelerate into an aging society [12]. Meanwhile, issues such as rapid urbanization, severe environment pressure, and increasing labor costs will further challenge the stability and sustainability of China's development. Given that the technical barriers for the popularization of construction automation technology have disappeared thanks to the rapid development of information technology and robotics, the construction automation technology will soon provide a great opportunity to 
tackle those critical issues. It is foreseeable that in the near future, construction automation technology will play a significant role in the development of China and beyond.

\section{REFERENCES}

[1] Marshall, C. "Pruitt-Igoe: the troubled high-Rise that came to define urban America - a history of cities in 50 buildings, day 21", The Guardian, 22 Apr. 2015, www.theguardian.com/cities/2015/apr/22/pruitt-igoe-high-rise-urban-america-history-cities, Accessed 13 Sept. 2017.

[2] Goettsch Partners, "300 East Randolph, Chicago, IL”, retrieved Sept. 13, 2017, from http://www.gpchicago.com/architecture/300-east-randolph/, Accessed 13 Sept. 2017.

[3] Lynch K., The image of the city, Harvard University Press, Cambridge, MA, USA, 1962.

[4] Bock T., "Robot oriented design of variable building kits", Proceedings of the 7th ISARC, ISARC 1990, Bristol, UK, 1:230-236, 1990.

[5] Kendall S., Teicher J., Residential Open Building, E\&FN Spon, 2000

[6] Bock, T., Linner, T., Robotic industrialization: automation and robotic technologies for customized component, module, and building prefabrication, New York, NY: Cambridge University Press, 2015

[7] Bock, T., Linner, T., Site automation: automated robotic on-site factories, New York, NY: Cambridge University Press, 2016

[8] Pan W., Proposed Solution for Implementing the Housing Industrialization Strategy in China, M.Sc. thesis, Technique University of Munich, Munich, Germany, 2013.

[9] Murray N., Fernando T., Ghassan A., "A virtual environment for the design and simulated construction of prefabricated buildings", Virtual Reality, 6(4): 244-256, 2003.

[10] Park K., Jang M., Lee, H., "An analysis of the optimal planning of material lifting in the high-rise building construction", Proceedings of Annual Conference of AIK, Seoul, South Korea, 2001.

[11] Neelamkavil J., "Automation in the Prefab and modular construction industry", Proceedings of the 26th Annual International Symposium on Automation and Robotics in Construction, 2009.

[12] Zeng Y., Hesketh T., "The effects of China's universal two-child policy", The Lancet, 388(10054):1930-1938, 2016. 